\title{
RELATIONSHIP OF TWO FACTORS AFFECTING OSSEOINTEGRATION OF IMMEDIATE IMPLANT
}

\author{
Walid Ahmed Ghanem*
}

\begin{abstract}
Background: Implant stability plays important role in the success of implant which is affected by peri-implant bone defect .Also the bone formation around the implant indicates the implant osseointegration condition.
\end{abstract}

Aim of the study: was aimed to evaluate the relation between horizontal gap ,implant stability and osseointegration of immediate implant.

Patient \& Methods: This study included 14 patients (8males and 6 females) average age was 32 years. 20 implants were inserted into 20 fresh extracted of maxillary non restorable single rooted teeth. Horizontal gap was measured immediately after implant insertion, stability and bone density of each implant were measured immediately, 3 and 6months postoperatively. All data were analyzed statistically.

Results: The mean of horizontal gap was $1.84 \pm 0.38$, implant stability measures were $58.35 \pm 4.53,64.9 \pm 2.63$ and $74.45 \pm 4.78$ while bone density were $1303.2 \pm 140.68,1609.15 \pm 122.84$ and 1963.25 \pm 127.13 immediately,3 \& 6 months postoperatively respectively. Horizontal gap results statistically showed reverse relation with implant stability \& bone density results. While implant stability results showed direct relation with bone density results.

Conclusion: Horizontal gap has reverse relation with implant stability \& osseointegration. While implant stability has direct relation with osseointegration.

KEY WORD: Horizontal gap, Implant stability, Oseointegratio, Immediate implant.

\section{INTRODUCTION}

Missing one tooth or more can be replaced by implant to restore the function, esthetic and psychic condition of the patient. One of the advantages of immediate implant insertion into the fresh extracted socket is to preserve the bony socket dimension and the surrounding soft tissue especially in esthetic zone. Normally there is difference between the diameter of bony socket and the selected implant diameter and this difference (gap around implant) if increase it may play role in implant osseointegration. Implant stability plays a critical role for successful

* Assistant Professor Oral \& Maxillofacial Surgery Dept., Faculty of Dentistry, Suez Canal University, Ismailia, Egypt 
osseointegration, which has been viewed as a direct structural and functional connection existing between bone and the surface of a load-carrying implant. (1) Primary stability of an implant comes from mechanical engagement with cortical bone. It is affected by the quantity and quality of bone that the implant is inserted into, surgical procedure, length, diameter, and form of the implant.(2) Many techniques can be used to measure the implant stability as Percussion test, Periotest and Ostell. Recently the most common technique can be used to measure the implant stability clinically and provides the feasibility for implant loading is Ostell with the use of resonance frequency analysis (RFA). The use of RFA may provide a possibility to individualize implant treatment with regards to healing periods, detecting failing implants, type of prosthetic construction, and if one- or twostaged procedures should be used. ${ }^{(3)}$ Bone density around inserted implant indicates the success of implant osseointegration as the bone density values increase, the success of implant osseointegration increase. Bone density can be measured by cone beam CT (CBCT). The relation among horizontal gap, implant stability and bone density is still the matter of research.

\section{Aim of the study}

This study was aimed to evaluate the relation between horizontal gap, implant stability and osseointegration of immediate implant.

\section{PATIENT \& METHODS}

This study included 14 patients ( 8 males and 6 females) average age was 32 years. 20 implants were inserted into 20 fresh extracted of maxillary non restorable single rooted teeth. The principles outlined in the Declaration of Helsinki on clinical research involving human subjects were followed. All patients received thorough explanations and signed a written informed consent form prior to being enrolled in the study. Healthy non smoker patients with good oral hygiene were involved in this study. Each patient was prepared by scaling and root planning, and mouth wash $0.12 \%$ chlorhexidine glucomat (CHX) was administrated four times daily, one week before tooth extraction. Oral regimen of antibiotic $1 \mathrm{gm}$ of Augmentin tablets was taken 2 hours before surgery. Fig. (1) After administration of local anesthesia, interdental papillae mesial and distal to the extracted tooth were elevated by mucoperiosteal elevator. Fig. (2) After atraumatic extraction, the fresh extracted bony socket dimensions were measured by caliber for horizontal dimension and gauge depth for vertical dimension. The appropriate implant was selected and horizontal gap around the implant was recorded, the range of horizontal gap was1-3 mm. Dentium (www.dentium.com) implant system was used (cylinder type). The pilot hole was drilled into fresh extracted bony socket using a twist drill of $1.8 \mathrm{~mm}$ diameter to the planed depth, then used gradually increasing drill diameter till reach final preparation for the selected implant dimension. The selected implant was inserted into the prepared bony socket and tightened by wrench into bone till the implant was firmly stabilized submerged $2 \mathrm{~mm}$ below alveolar socket crest. Fig. (3) Transducer (smart peg) was introduce to the inserted implant and the implant stability values were measured by Ostell (Osstell ISQ, AB, Gamlestadsvagen 3B, SE-41502 Goteborg, Sweden). Two readings were recorded (mesio-distal and labio/ bucco-palatal measures).

The cover screw was screwed in place. Interdental papillae mesial and distal to each implant were sutured in an interrupted matters suture using black silk suture material which was removed after one week postoperatively. Fig. (4)

Patients were instructed to apply cold packs over the surgical area extra-orally $15 \mathrm{~min} / \mathrm{hr}$. for the first six hours post-operatively. Oral regimen of Augmentin1gm/ 12hr was continued for five days 
post-operatively. Anti-inflammatory (Cataflam $50 \mathrm{mg}$ ) tablet was given two times/day for five days post-operatively. After the first twenty-four hours patients were instructed to use $0.12 \%$ chlorexidine glucomat mouth wash 2 times daily for 15 days. Any prosthesis was not allowed to be worn until they had been adjusted and refitted not sooner than 2 weeks after surgery.

Patients were viewed 24 hours after surgery to evaluate clinically the post-operative complications as redness, edema, swelling at surgical site, wound dehiscence, pain, discomfort or implant looseness.

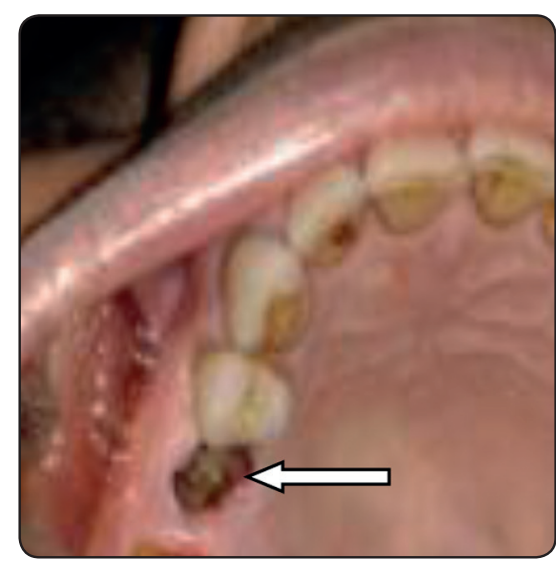

Fig. (1) Show preoperative remaining root of upper right second premolar (white arrow)

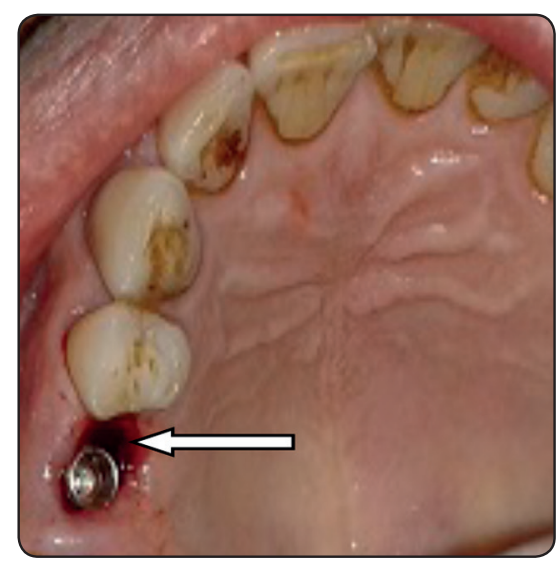

Fig. (3) Show horizontal defect around the submerged implant (white arrow)
Regular check-ups were done on weekly bases during the first month then after $3 \& 6$ months postoperatively. CBCT was done immediately postoperative and after, three and six months postoperatively. The CBCT was used to measure the bone density around implant.

The implant stability of each implant was measured by Osstell (ISQ) after three and six months postoperatively. All gathered data were statistically analyzed. Two tailed T-test and ANOVA tests were used.

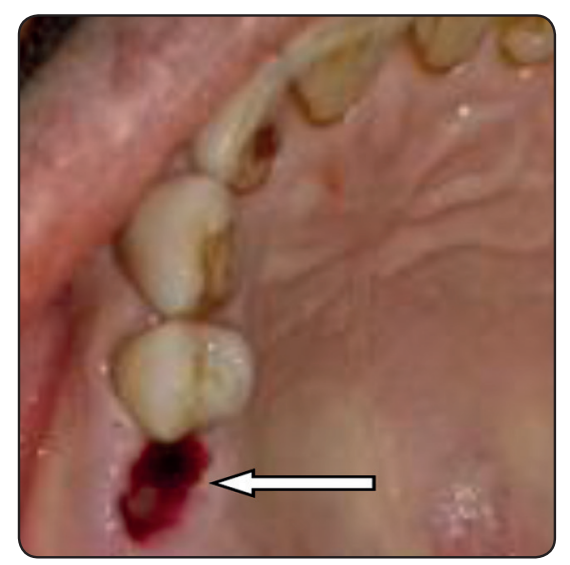

Fig. (2) Show socket after atraumatic extraction(white arrow)

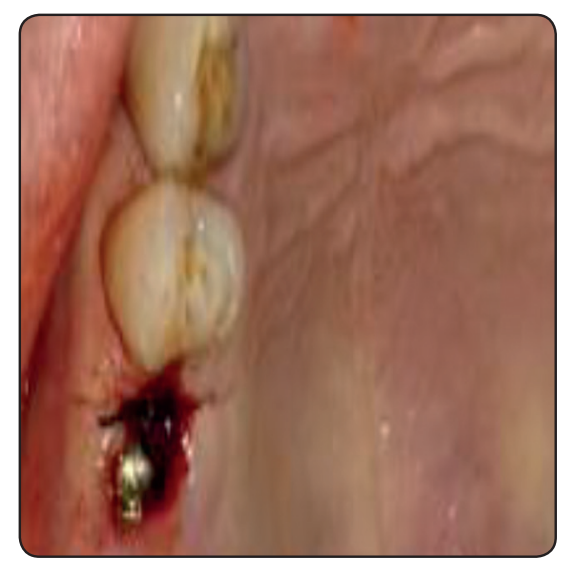

Fig. (4) Show interrupted suture mesial to the inserted implant 


\section{RESULTS}

After 6 months follow up, a survival rate of $100 \%$ was reported for all implants. Normal wound healing was established throughout the whole study except 2 cases showed minor swelling for the first day postoperative. No wound dehiscence, erythema, implant looseness or pain was recorded. The mean \&standard deviation values of horizontal gap was $1.842 \pm 0.381$. Immediately postoperative, the mean and standard deviation values of implant stability and bone density were 58.35 $\pm 4.53,1303.2 \pm 140.68$ respectively. Fig. (5) While after three months the mean and standard deviation values of implant

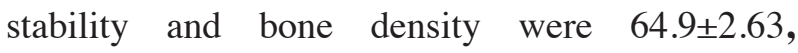
$1609.15 \pm 122.84$ respectively (Table 1). After six months the mean and standard deviation values of implant stability and bone density were $74.45 \pm 4.78$, 1963.25 \pm 127.13 respectively. Fig. (5,6) Horizontal gap showed negative correlation with implant stability as - $0.102,-0.270$ immediately and after three months respectively, but showed positive correlation 0.024 after six months postoperatively. Also Horizontal gap showed negative correlation with bone density as $-0.125,-0.214,-0.256$ through the whole study intervals. (table 2) According to

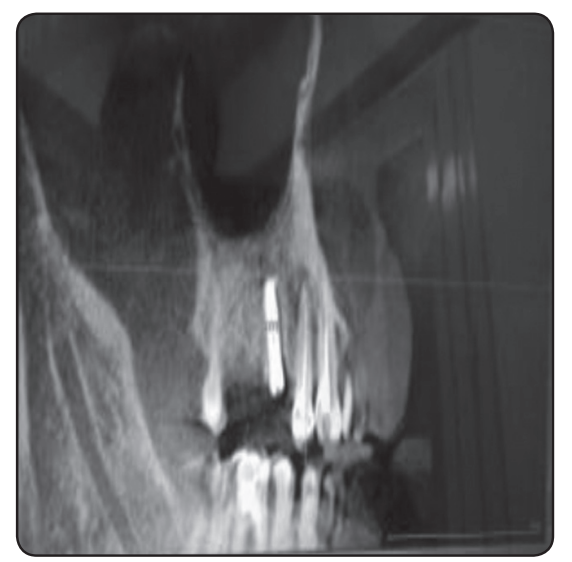

Fig (5) Show bone density values around the implant measured by CBCT (Sirona, Galileos, 3D, Cone Beam X-ray machine) the results the horizontal gap measures inversely proportion to implant stability and bone density measures. While implant stability measures showed positive correlation with bone density measures. So there is direct proportion with high significance between implant stability measures and bone density measures which indicated that increase in implant stability measures concomitant with increase in bone density as well as implant osseointegration.

TABLE (1) Show values of horizontal gap, bone density and implant stability throughout study intervals.

Descriptive Statistics

\begin{tabular}{|l|c|c|c|}
\hline & Mean & $\begin{array}{c}\text { Std. } \\
\text { Deviation }\end{array}$ & N \\
\hline Horizotal Gap mm & 1.8425 & .38157 & 20 \\
Bone Density IMM & 1303.20 & 140.689 & 20 \\
Bone Density 3 months & 1609.15 & 122.845 & 20 \\
Bone Density 6 month & 1963.25 & 127.136 & 20 \\
Implant Stability IMM & 58.35 & 4.534 & 20 \\
Implant Stability 3months & 64.90 & 2.634 & 20 \\
Implant Stability 6 month & 74.45 & 4.785 & 20 \\
\hline
\end{tabular}

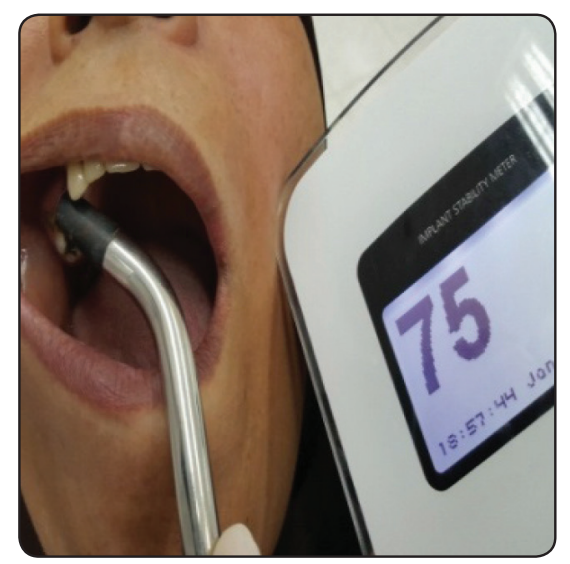

Fig. (6) Show postoperative implant stability values measured by Ostell device 
TABLE (2) Show correlations of horizontal gap, bone density and implant stability throughout study intervals.

\section{Correlations}

\begin{tabular}{|c|c|c|c|c|c|c|c|c|}
\hline & & $\begin{array}{l}\text { Horizotal } \\
\text { Gap mm }\end{array}$ & $\begin{array}{c}\text { Bone } \\
\text { Density } \\
\text { IMM }\end{array}$ & $\begin{array}{c}\text { Bone } \\
\text { Density } \\
3 \text { months }\end{array}$ & $\begin{array}{c}\text { Bone } \\
\text { Density } \\
6 \text { months }\end{array}$ & $\begin{array}{c}\text { Implant } \\
\text { Stability } \\
\text { IMM }\end{array}$ & $\begin{array}{l}\text { Implant } \\
\text { Stability } \\
3 \text { months }\end{array}$ & $\begin{array}{l}\text { Implant } \\
\text { Stability } \\
6 \text { months }\end{array}$ \\
\hline \multirow[t]{3}{*}{$\begin{array}{l}\text { Horizotal } \\
\text { Gap mm }\end{array}$} & $\begin{array}{l}\text { Pearson } \\
\text { Correlation }\end{array}$ & 1 & -.125 & -.214 & -.256 & -.102 & -.270 & .024 \\
\hline & 5ig.(2-tailed) & & .600 & .364 & .275 & .669 & .249 & .921 \\
\hline & $\mathrm{N}$ & 20 & 20 & 20 & 20 & 20 & 20 & 20 \\
\hline \multirow{3}{*}{$\begin{array}{c}\text { Bone } \\
\text { Density } \\
\text { IMM }\end{array}$} & $\begin{array}{l}\text { Pearson } \\
\text { Correlation }\end{array}$ & -.125 & 1 & $.800 * *$ & $.704 * *$ & $.919 * *$ & $.626 * *$ & $.646 * *$ \\
\hline & Sig.(2-tailed) & .600 & & .000 & .001 & .000 & .003 & .002 \\
\hline & $\mathrm{N}$ & 20 & 20 & 20 & 20 & 20 & 20 & 20 \\
\hline \multirow{3}{*}{$\begin{array}{c}\text { Bone } \\
\text { Density } 3 \\
\text { months }\end{array}$} & $\begin{array}{l}\text { Pearson } \\
\text { Correlation }\end{array}$ & -.214 & .800 & 1 & $.553^{*}$ & $.893 * *$ & $.811 * *$ & $.571 * *$ \\
\hline & Sig.(2-tailed) & .364 & .000 & & .011 & .000 & .000 & .009 \\
\hline & $\mathrm{N}$ & 20 & 20 & 20 & 20 & 20 & 20 & 20 \\
\hline \multirow{3}{*}{$\begin{array}{c}\text { Bone } \\
\text { Density } \\
6 \text { month }\end{array}$} & $\begin{array}{l}\text { Pearson } \\
\text { Correlation }\end{array}$ & -.256 & .704 & $.553 *$ & 1 & $.713 * *$ & $.511 * *$ & $.888 * *$ \\
\hline & Sig.(2-tailed) & .275 & .001 & .011 & & .000 & .021 & .000 \\
\hline & $\mathrm{N}$ & 20 & 20 & 20 & 20 & 20 & 20 & 20 \\
\hline \multirow{3}{*}{$\begin{array}{l}\text { Implant } \\
\text { Stability } \\
\text { IMM }\end{array}$} & $\begin{array}{l}\text { Pearson } \\
\text { Correlation }\end{array}$ & -.102 & $.919 »$ & $.893 * *$ & $.713 * *$ & 1 & $.748 * *$ & $.774 * *$ \\
\hline & Sig.(2-tailed) & .669 & .000 & .000 & .000 & & .000 & .000 \\
\hline & $\mathrm{N}$ & 20 & 20 & 20 & 20 & 20 & 20 & 20 \\
\hline \multirow{3}{*}{$\begin{array}{l}\text { Implant } \\
\text { Stability } \\
\text { 3months }\end{array}$} & $\begin{array}{l}\text { Pearson } \\
\text { Correlation }\end{array}$ & -.270 & .626 & $.811 * *$ & $.511 *$ & $.748 * *$ & 1 & $.551 *$ \\
\hline & Sig.(2-tailed) & .249 & .003 & .000 & .021 & .000 & & .012 \\
\hline & $\mathrm{N}$ & 20 & 20 & 20 & 20 & 20 & 20 & 20 \\
\hline \multirow{3}{*}{$\begin{array}{l}\text { Implant } \\
\text { Stability } \\
6 \text { month }\end{array}$} & $\begin{array}{l}\text { Pearson } \\
\text { Correlation }\end{array}$ & .024 & .646 & $.571 * *$ & $.888 * *$ & $.774 * *$ & $.551 *$ & 1 \\
\hline & Sig.(2-tailed) & .921 & .002 & .009 & .000 & .000 & .012 & \\
\hline & $\mathrm{N}$ & 20 & 20 & 20 & 20 & 20 & 20 & 20 \\
\hline
\end{tabular}

** Correlation is significant at the 0.01 level (2-tailed). *. Correlation is significant at the 0.05 level (2-tailed). 


\section{DISCUSSION}

The distance between fresh extracted bony socket and the immediate implant is called peri-implant gap. The fresh socket is wider than the implant diameter, which causes the peri-implant gap that influences stability and osseointegration ${ }^{[4,5]}$. This gap exists at the most coronal level to bone implant contact. The gap size is an important determinant with respect to predictability of spontaneous bone fill. The critical gap size that allows unaided healing has not been determined, because there are variables that can affect the result. Wilson et al $1998{ }^{(6)}$ supplied the first human histological documentation that osseointegration occurred between the newly formed bone in the gap and an immediately placed implant. Subsequently, Wilson et al $2003^{(7)}$ assessed rough surface implants $(\mathrm{N}=10)$ where the gap was covered with a connective tissue graft and the area was covered with a flap. They found that Osseo integration, BIC, and bone fill were similar when gaps were $<1.5 \mathrm{~mm}$ and $>4 \mathrm{~mm}$. Schenk and Willengger $1977^{(8)}$ conducted a study on rabbits and observed the lack of complete bone formation with peri-implant gaps wider than $1.0 \mathrm{~mm}$. Carlsson et al. $1988^{\left({ }^{9}\right)}$ used the same experimental model to compare 3 values of peri-implant gap between bone and implant (group $\mathrm{A}-0 \mathrm{~mm}$, group $\mathrm{B}-0.35 \mathrm{~mm}$, and group $\mathrm{C}-0.85 \mathrm{~mm}$ ) and observed residual gaps in groups B and C at 6 and 12 weeks after surgery. Ferrus et al 2010(10), De Barros et al 2012 (11)

Ferrus et al 2010 ${ }^{(10)}$, De Barros et al $2012^{(11)}$ in their experimental studies in dogs, they noted that bigger gaps have a greater potential for incomplete bone fill; therefore, they suggested biomaterial filler would be beneficial in large gaps.

While Wilson et al $2003^{(7)}$, Botticelli et al 2004 ${ }^{(12)}$ in their studies demonstrated that the horizontal gap was initially filled with bone without bone grafts in defects $\geq 3 \mathrm{~mm}$. This agrees with the present study as the horizontal gaps were filled by bone without bone graft after six months and the range of horizontal gap was 1-3 mm.
Akimoto et al. $1999^{(13)}$ placed post-extraction implants in dogs and evaluated the repair of periimplant gaps from 0.5 to $1.4 \mathrm{~mm}$ after 12 weeks. They concluded that the defect size is inversely proportional to the bone/implant contact. This agrees with the present study results as the correlation was negative between horizontal gap and osseointgration which indicated that the increase in horizontal gap defect the slower bone formation to fill the defect around the implant but at the end of study the correlation became positive which indicated that the peri-implant defect was filled by bone. Consistent with the present study findings Boticelli et al $2003^{(4)}$ demonstrated that horizontal gap defect $\geq 3 \mathrm{~mm}$ could completely resolve after 4 months of healings in humans without the use of bone grafting materials or membrane barrier. Stability both at placement and during function is an important criterion for the success of dental implant. ${ }^{(14)}$ Primary stability requires excellent bone-to-implant contact at the time of implant placement and is essential to resist micromotion and for subsequent osseointegration..$^{(15)}$

The stability of implants was measured by the resonance frequency (RFA) has been found to be the most accurate method. The RFA values are represented by a quantitative unit called the ISQ on a scale from1 to 100; an increased ISQ value indicates increased stability. ${ }^{(16)}$

Aldosari $2011^{(17)}$ concluded that the resonance frequency analysis technique can supply clinically relevant information about the state of the implantbone interface at any stage of the treatment or at follow-up examinations. The resonance frequency analysis technique evaluates implant stability as a function of the stiffness of the implant-bone interface and is influenced by factors such as bone density, jaw healing time and exposed implant height above the alveolar crest.

Sennerby and Meredith $2000^{(18)}$ found that lower initial stability will normally increase with time due 
to the lower mechanical stability being enforced by the bone remodeling process. This agrees with the present study results as the implant stability showed low RFA values initially with peri-implant gap defect increase in size but increase in values has been recorded gradually through the study intervals.

Farré-Pagéset al $2011^{(19)}$ found that higher bone density favors greater primary stability, with the least dense bone typically found in the posterior maxilla.

Nkenke et al $2003^{(20)}$, Gedrange et al $2005^{(21)}$ studies had shown that RFA values did correlate with the surface of BIC, and with the height of the crestal cortical bone penetrated by the implants in the oral aspects of the implant sites. This agrees with the present study results which showed positive correlation between implant stability and bone density around implant (osseointegration) throughout study intervals.

\section{CONCLUSION}

Horizontal gap has reverse relation with implant stability \& osseointegration. While implant stability has direct relation with osseointegration.

\section{REFERENCES}

1- Sennerby L., Roos J.: Surgical determinants of clinical success of osseointegrated oral implants: A review of the literature. Int J prosth 1998;11: 408-420

2- Meredith N.: Assessment of implant stability as a prognostic determinant. Int J prosth 1998;11: 491-501.

3- Heo SJ, Sennerby L, Odersjo M.: Stability measurements of craniofacial implants by means of resonance frequency analysis. A clinical pilot study. J Laryngol Otol 1998; 112(6): 537-542.

4- Botticelli D., Berglundh T., Buser D., Lindhe J.: The jumping distance revisited: an experimental study in the dog," Clin Oral Implants Res, 2003;14( 1 ): 35-42

5- Botticelli D., Renzi A., Lindhe J., Berglundh T.: Implants in fresh extraction sockets: a prospective 5-year follow-up clinical study," Clin Oral Implants Res 2008;19 (12):1226-1232
6- Wilson TG., Schenk R, Buser D.: Implants placed in immediate extraction sites: a report of histologic and histometric analyses of human biopsies. Int $\mathrm{J}$ Oral Maxillofac Implants. 1998;13:333-341.

7- Wilson TG., Carnio J, Schenk R.: Immediate implants covered with connective tissue membranes: human biopsies. J Periodontol. 2003;74:402-409.

8- Schenk RK., Willenegger HR.: Histology of primary bone healing: modifications and limits of recovery of gaps in relation to extent of the defect. Unfallheilkunde, 1977; 80(5): 155-160

9- Carlsson L., Rostlund T., Albrektsson B., Albrektsson T.: Implant fixation improved by close fit. Cylindrical implantbone interface studied in rabbits. Acta Orthopaedica Scandinavica, 1988;59( 3) :. 272-275

10- Ferrus J, Cecchinato D, Pjetursson EB.: Factors influencing ridge alterations following immediate implant placement into extraction sockets. Clin Oral Implants Res. 2010;21:22-29.

11- De Barros RR, Novaes AB Jr, Queiroz A :Early periimplant endosseous healing of two implant surfaces placed in surgically created circumferential defects. A histomorphometric and fluorescence study in dogs. Clin Oral Implants Res. 2012;23:1340-1351

12. Botticelli D, Berglundh T, Lindhe J.: Hard-tissue alterations following immediate implant placement in extraction sites. J Clin Periodontol. 2004; 31:820-828

13- Akimoto K., Becker W., Persson R., Baker D A., Rohrer M D., O'Neal RB.: Evaluation of titanium implants placed into simulated extraction sockets: a study in dogs. Int J Oral Maxillofac Implants. 1999;14, ( 3) :351-360

14- Meredith N, Alleyne D, Cawley P.: Quantitative determination of the stability of the implant-tissue interface using resonance frequency analysis. Clin Oral Implants Res 1996;7:261-267.

15- Szmukler-Moncler S, Salama H, Reingewirtz Y, Dubruille JH.: Timing of loading and effect of micro-motion on boneimplant interface. A review of experimental literature. J Biomed Mat Res. 1998;43:192-203.

16- Meredith N., Book K., Friberg B. :Resonance frequency measurements of implant stability in vivo. A crosssectional and longitudinal study of resonance frequency measurements on implants in the edentulous and partially dentate maxilla. Clin Oral Implants Res 1997;8:226-233. 
17- Aldosari A.: Influence of an adapted surgical technique on the stability of dental implants : Astudy in beagle dogs. J PDA. $2011 ; 20(4)$ : 254-259

18- Sennerby L, Meredith N.: Implant stability measurements using resonance frequency analysis: biological and biomechanical aspects and clinical implications. Periodontol 2000 , 2008;47:51-66.

19- Farré-Pagés N, Augé-Castro ML, Alaejos-Algarra F, Mareque-Bueno J, Ferrés-Padró E, Hernández-Alfaro F.: Relation between bonedensity and primary implant stability. Med Oral Patol Oral Cir Bucal. 2011;16(1):62-67.
20- Nkenke E, Hahn M, Weinzierl K, Radespiel-Tro“"ger M, Neukam FW, Engelke K.: Implant stability and histomorphometry: a correlation study in human cadavers using stepped cylinder implants. Clin Oral Implants Res 2003; 14:601-609.

21- Gedrange T, Hietschold V, Mai R, Wolf P, Nicklisch M, Harzer W.: An evaluation of resonance frequency analysis for the determination of the primary stability of orthodontic palatal implants. A study in human cadavers. Clin Oral Implants Res 2005; 16:425-431. 